\title{
Design and Analysis of Electromagnetic Tubular Linear Actuator for Higher Performance of Active Accelerate Pedal
}

\author{
Jae-Yong Lee, Jin-Ho Kim*, and Jeh-Won Lee \\ School of Mechanical Engineering, Yeungnam University, Gyeongsangbukdo 712-749, Korea
}

(Received 11 November 2009, Received in final form 18 December 2009, Accepted 21 December 2009)

\begin{abstract}
This paper describes the design and analysis of a tubular linear actuator for intelligent AAP (Active Accelerate Pedal) system. In a driving emergency, the electromagnetic actuator produces an additional pedal force such as the active pedal force and vibration force to release the driver's foot on accelerator pedal. A prior study found that the linear actuator with a ferromagnetic core had a problem in transferring the additional force naturally to a driver due to the cogging force. To reduce the cogging force and obtain higher performance of the AAP system, a coreless tubular linear actuator is suggested. Electromagnetic finite element analysis is executed to analyze and design the coreless tubular actuator, and dynamic analysis is performed to characterize the dynamic performance of the AAP system with the suggested tubular actuator for two types of thrust force.
\end{abstract}

Keywords : tubular linear actuator, active accelerate pedal, electromagnetic field analysis, finite element analysis, cogging force

\section{Introduction}

Automobile companies have developed a wide range of technologies to reduce accident frequency and casualties. Car accidents are generally caused by the driver's improper control of the vehicle, and not by hardware technology problems. Human logical thinking is the most important factor affecting the increase or decrease of accident frequency.

Of the five human senses, three senses, the sight, hearing and touch, are used to control a car, and of these three, the sense of touch warns a driver more directly and quickly than the senses of sight and hearing.

AAP (Active Accelerate Pedal) induces deceleration by transferring the hazard warning to the driver's foot so that the driver drives the car within the safety speed limit when the driver drives over the safety speed limit. If a car goes faster than the turning speed limit on a curve or drives in the unsafe short distance zone from the car ahead, AAP produces a counterforce to the accelerate pedal, and the driver is made to release his foot from the pedal, causing the car to decelerate.

AAP technology has been applied to some car models

*Corresponding author: Tel: +82-53-810-2441

Fax: +82-53-810-4627, e-mail: jinho@ynu.ac.kr made by EU, Japan and Korea car companies [1, 2]. This system uses a rotary type actuator composed of a spring or geared system to produce the warning or counterforce. AAP with the geared system has critical drawbacks such as inaccurate movement and backlash due to the high gear ratio [3]. To overcome the inherent drawback of the rotary actuator, AAP system using a tubular linear actuator with a ferromagnetic core was introduced [4], but even this new system still had the cogging torque problem during operation.

This research suggests a new type of coreless tubular electromagnetic linear actuator. Its design is optimized to overcome the cogging torque problem and enhance the performance of the AAP system. Finite element analysis is performed to analyze and design the newly suggested tubular actuator, which is the coupled to electric, magnetic and mechanical subsystem. In addition, the dynamic characteristic of the AAP system with the proposed actuator is evaluated by the dynamic analysis commercial software, RecurDyn.

\section{Design Conditions of Actuator in AAP}

\subsection{System Organization}

The AAP is based on the concept of a system of active safety, which induces natural deceleration in dangerous 


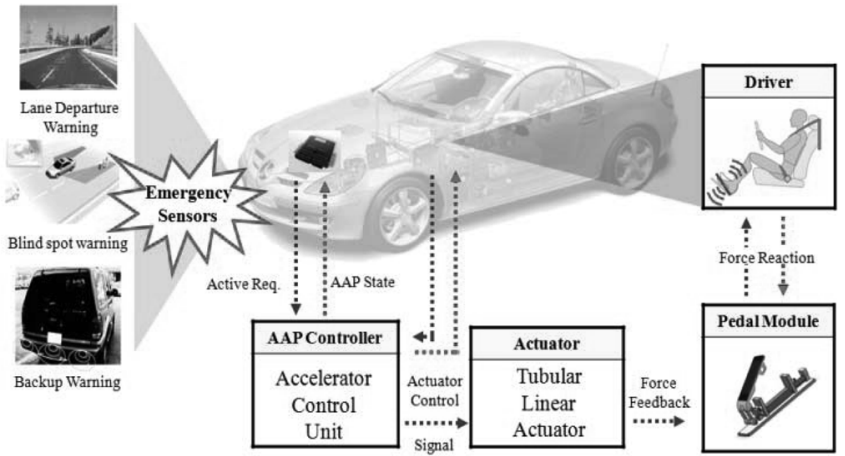

Fig. 1. Schematic Diagram of the Development of an Actuator for Active Accelerate Pedal System.

situations like going over the limitation speed and being in a crash with the car ahead. Fig. 1 shows a schematic diagram of the AAP system, which consists of an emergency sensor, accelerator control unit, actuator and pedal module.

\subsection{Hysteresis and Active Operation}

When the AAP system is operating, the accelerate pedal has to transmit a counterforce so that the driver is able to feel an impact or vibration on his foot.

As shown in Fig. 2, the passive pedal hysteresis curve is adopted for a passive condition, in which the actuator is inactive, and the active pedal force curve is adopted for an active condition, in which the actuator is active. A spring in a pedal module creates hysteresis force which makes the pedal come back to the original position with a lower force than the pressing force on the pedal.

\subsection{Active Accelerate Operation}

In Fig. 2, there are two types of the additional pedal counterforce, the active pedal force and the active pedal force $\&$ vibration force. The active pedal force produces a continuous counterforce when the pedal is operated at low

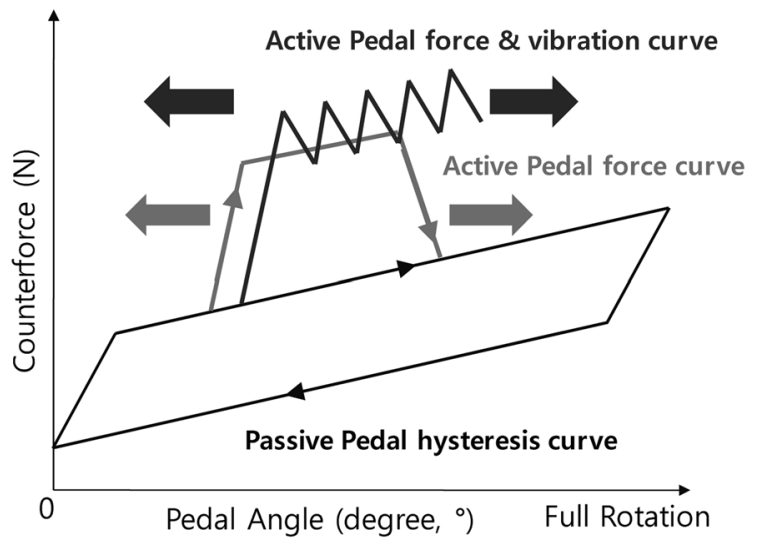

Fig. 2. Active and Passive Pedal Force Curve.
Table 1. AAP Design Requirements and TLA size conditions.

\begin{tabular}{cccc}
\hline \hline Title & Value & Title & Value \\
\hline Passive counterforce & $17 \sim 35 \mathrm{~N}$ & Hysteresis force & $7 \sim 15 \mathrm{~N}$ \\
Additional force & $15 \mathrm{~N}$ & Pedal rotating angle & $25^{\circ}$ \\
TLA moving stroke & $30 \mathrm{~mm}$ & Width & $<100 \mathrm{~mm}$ \\
Length & $<300 \mathrm{~mm}$ & Height & $<90 \mathrm{~mm}$ \\
\hline
\end{tabular}

speed, while the active pedal force $\&$ vibration produces a vibrating counterforce to transfer a relatively strong warning force when the pedal is operated at fast speed.

Table 1 shows the basic design conditions required to operate the AAP and the scope of the actuator size limitation according to the actuator operation conditions.

\section{Analysis and Design of Actuator}

\subsection{Coreless Tubular Electromagnetic Actuator}

Fig. 3 shows the schematic diagram of a coreless tubular linear actuator. The actuator consists of a mover and stator. The mover is made of $\mathrm{NdFe} 35$ permanent magnets which an aluminum tube encloses and the stator including coils can produce the electromagnetic force. The magnetized direction of permanent magnets is shown as a pair of SN-NS. The electromagnetic coils are energized in two phases displayed as A and B in Fig. 3. The mover transfers the additional force produced by input currents to the pedal. The force created by the input currents is so called the Lorentz force. The design variables are the length of the magnet, the outer diameter of the magnet and the inner and outer diameter of the coil part. The airgap is determined from the outer diameter of the magnet and the inner diameter of the coil part.

\subsection{Actuator Operation by Input Currents}

The mover of the TLA (tubular linear actuator) should move freely if currents are not induced, but if currents are induced, the mover should transfer the force to the axial direction. In this design, the steel yoke is not utilized to reduce the cogging force. The Lorentz force equation (1)

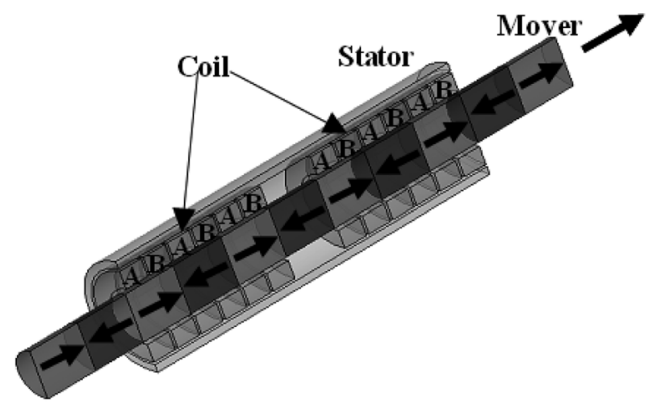

Fig. 3. Section view of the Tubular Linear Actuator. 


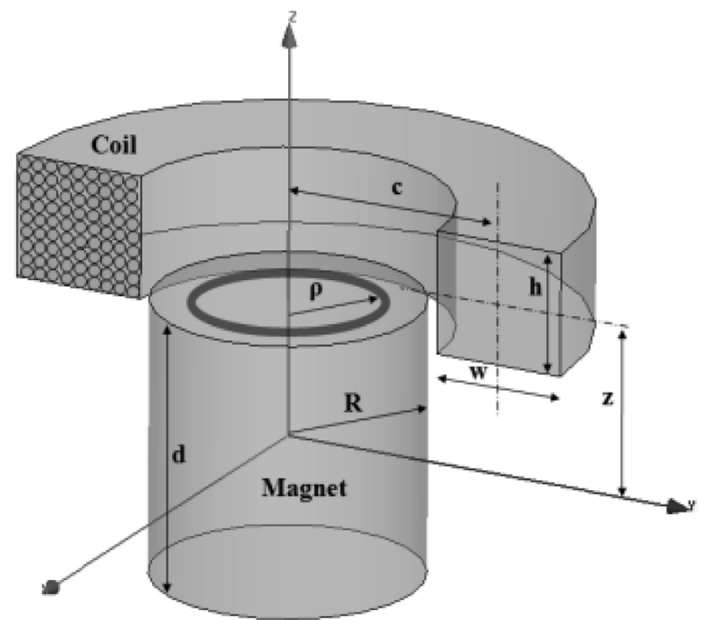

Fig. 4. Design parameters between magnet and current-carrying coil.

consists of the current induced to the coil and the interaction between the current and the magnets [4].

$$
F=\int(J \times B) d V
$$

For the operating condition of the actuator, the two phase work - not the force by the interaction between the magnet and coils - is analyzed. Using equation (1), equation (2) gives the force that is produced for the same condition applied in Fig. 4.

$$
\begin{aligned}
& f_{z}=\left(\frac{J\left(\mu_{o} M\right)}{4 \pi}\right) \int_{c-\frac{w}{2}}^{c+\frac{w}{2}} \int_{z-\frac{h}{2}}^{z+\frac{h}{2}} \int_{0}^{2 \pi} \frac{d}{d r}(L-U) r d \phi d z d r \\
& L=\int_{0}^{R} \int_{0}^{2 \pi} \frac{\rho}{(z-d / 2)^{2}+r^{2}+\rho^{2}-2 r \rho \cos (\theta-\phi)} d \theta d \rho \\
& U=\int_{0}^{R} \int_{0}^{2 \pi} \frac{\rho}{(z+d / 2)^{2}+r^{2}+\rho^{2}-2 r \rho \cos (\theta-\phi)} d \theta d \rho
\end{aligned}
$$

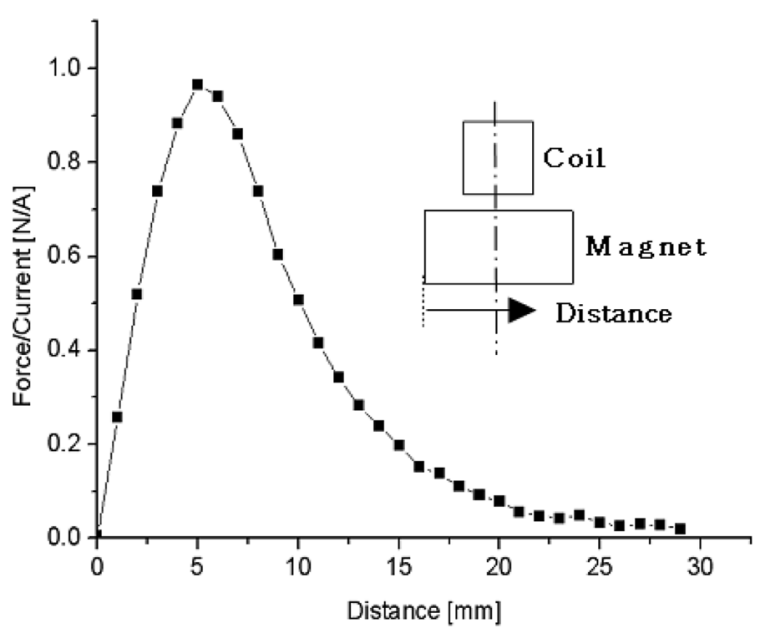

Fig. 5. Force/Current with a change in the position of the magnet.

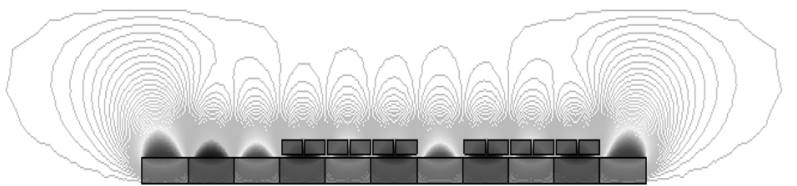

Fig. 6. Electromagnetic analysis of tubular linear actuator using MAXWELL software.

Fig. 5 shows the static finite element analysis result of the electromagnetic force with $1 \mathrm{~mm}$ movement of the magnet in the axial direction at induced current of $3 \mathrm{~A}$ [5].

\subsection{Electromagnetic Analysis of TLA for Determina- tion of Optimized Dimensions}

The suggested design must satisfy the constraint of the design dimensions, so it is optimized according to the change of the design variables. The design in the static mode was analyzed by finite element analysis, which was carried out with electromagnetic analysis software MAXWELL 2D.

Fig. 6 shows the result of the electromagnetic analysis with the finite element method. Design variables are the magnet length and radius, coil thickness and airgap. The analysis was performed by changing the dimensions of these variables in the design variable limit.

Fig. 7 shows the thrust force according to the size of the magnet axial length ranging from 0 to $5 \mathrm{~mm}$. On the graph, the magnet length increases from $18 \mathrm{~mm}$ to $24 \mathrm{~mm}$ and the maximum thrust force for the most part is at 1 $\mathrm{mm}$ distance movement. Therefore, a stable force was produced at the length of $22 \mathrm{~mm}$. The analysis of the magnet length was performed to $24 \mathrm{~mm}$ because it is trending toward lower thrust force at $1 \mathrm{~mm}$.

Fig. 8 shows the thrust force according to the size of the

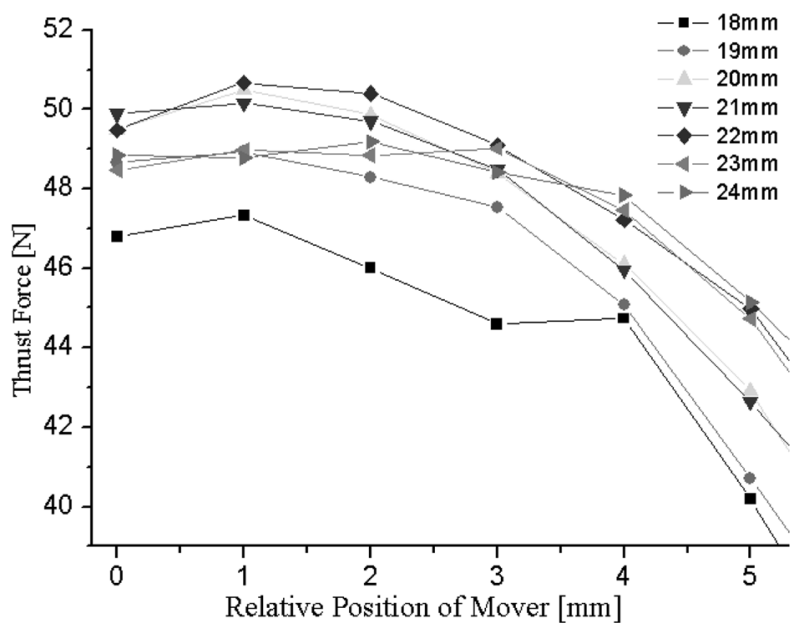

Fig. 7. Thrust force of the mover as a function of the position of the mover for different magnet axial lengths. 


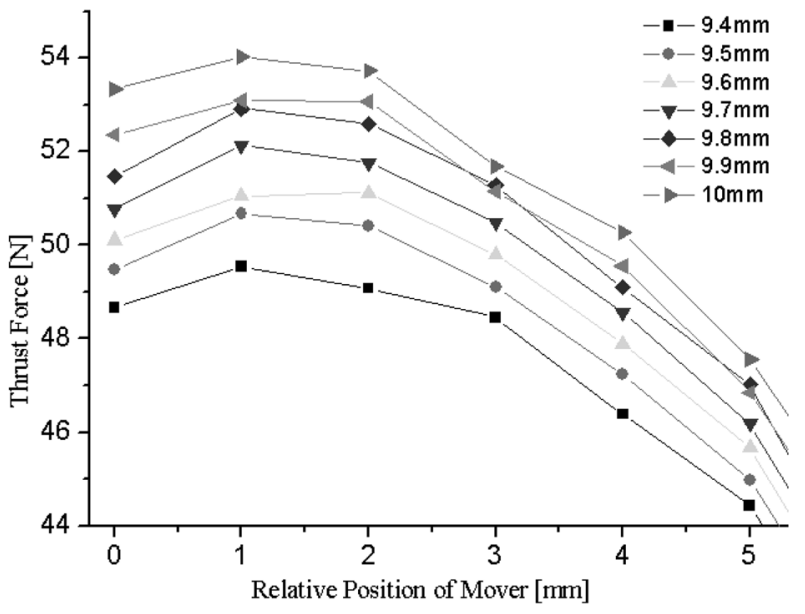

Fig. 8. Thrust force of the mover as a function of the position of the mover for different magnet radii.

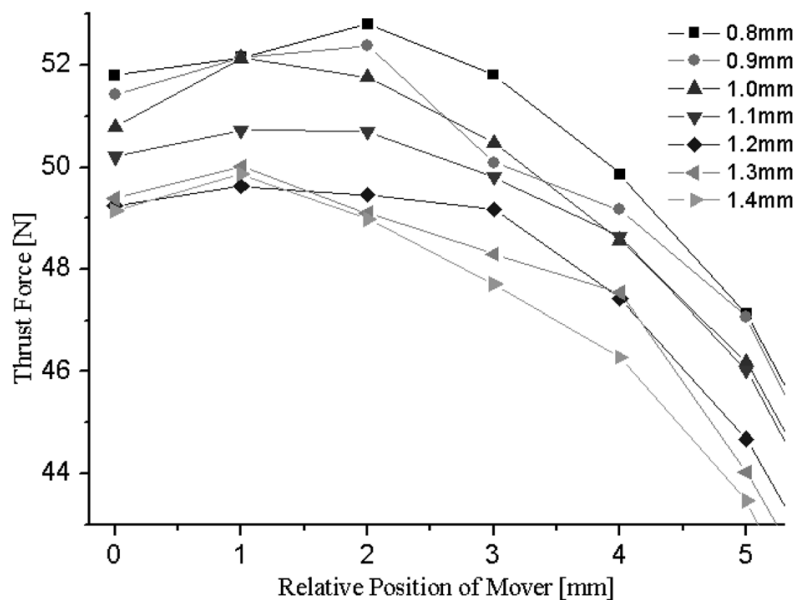

Fig. 9. Thrust force of the mover as a function of the position of the mover for different airgap lengths.

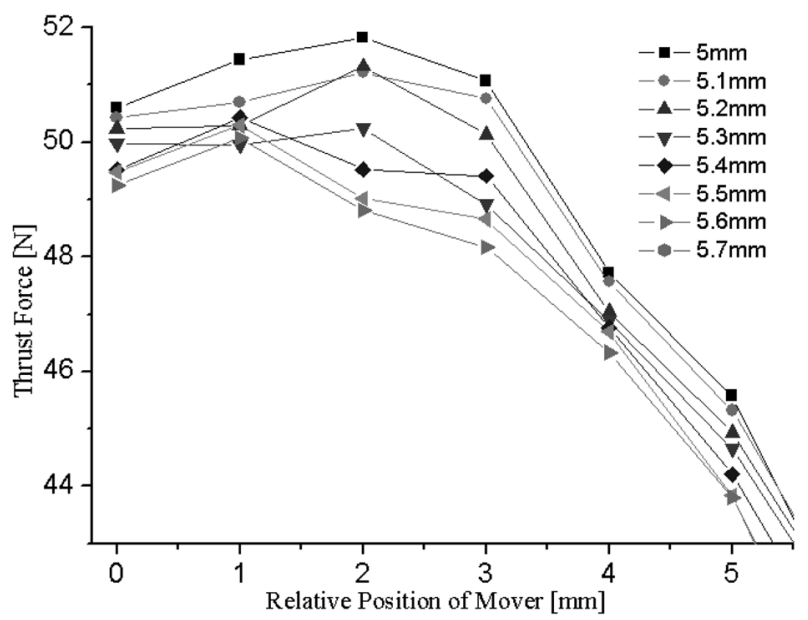

Fig. 10. Thrust force of the mover as a function of the position of the mover for different coil thicknesses.

magnet radius length. Every value over $9.6 \mathrm{~mm}$ satisfies to the requested thrust force of $50 \mathrm{~N}$. The thicker the
Table 2. Analysis Result of Design Variables.

\begin{tabular}{cccc}
\hline \hline Title & Value & Title & Value \\
\hline Magnet Axial Length & $22 \mathrm{~mm}$ & Airgap & $1.1 \mathrm{~mm}$ \\
Magnet Radial Length & $9.7 \mathrm{~mm}$ & Coil thickness & $5.2 \mathrm{~mm}$ \\
\hline
\end{tabular}

length of the magnet radius was, the heavier the weight of the whole actuator. The radius of $9.7 \mathrm{~mm}$ was selected.

Fig. 9 shows the thrust force according to the size of the airgap length. The airgap under $1.1 \mathrm{~mm}$ was able to satisfy the condition of requested thrust force. If the airgap is too narrow, manufacturing becomes difficult and the cost of manufacturing goes high.

In Fig. 10, the coil thickness of over $5.3 \mathrm{~mm}$ did not satisfy the condition of requested thrust force. Therefore, the shortest length $5.2 \mathrm{~mm}$ which is over $50 \mathrm{~N}$ in $3 \mathrm{~mm}$ stroke was chosen.

Therefore, the design variables from the result of the electromagnetic analysis are listed in Table 2.

\section{Simulation of AAP System with Coreless Tubular Linear Actuator}

\subsection{Cogging force analysis of the movement of the shaft}

There is considerable cogging force in the tubular actuator with a core [6]. The cogging force is about $0.125 \mathrm{~N}$ on average, for shaft movement of $30 \mathrm{~mm}$ stroke length in Fig. 11. It has an effect on the thrust force; it acts as a resistant force. A coreless model, analyzed with Maxwell, electromagnetic analysis program, is used to determine the cogging force to compare with that of a core model. The average cogging force of a tubular coreless actuator is about $0.01 \mathrm{~N}$. Fig. 11 shows the cogging

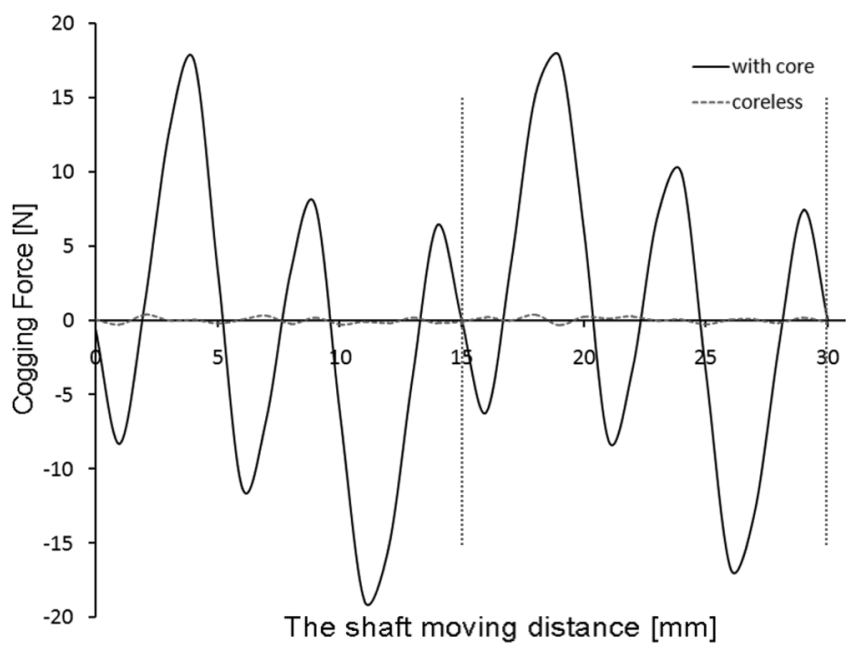

Fig. 11. Cogging force variation according to the movement distance of the shaft. 


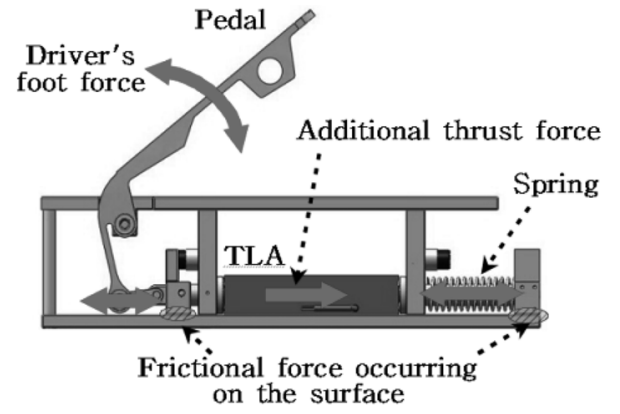

Fig. 12. The design of AAP system with tubular linear actuator.

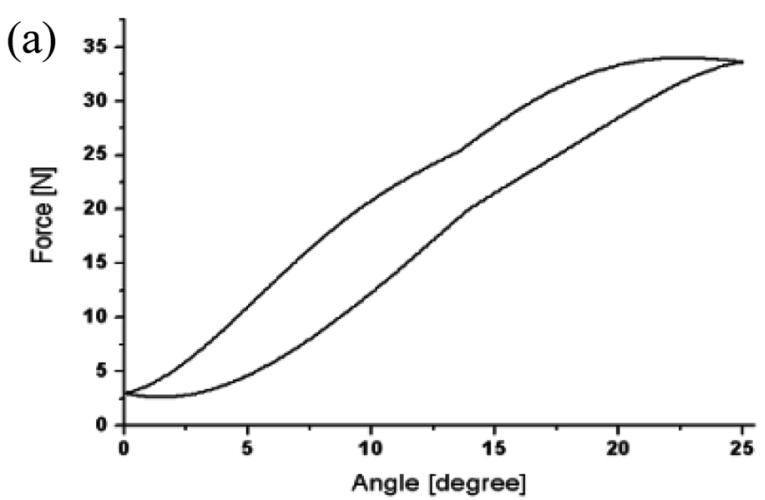

(b)

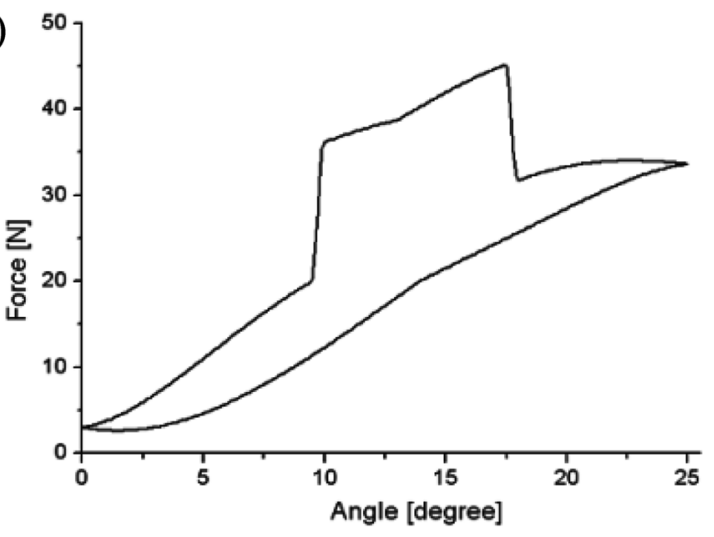

(c)

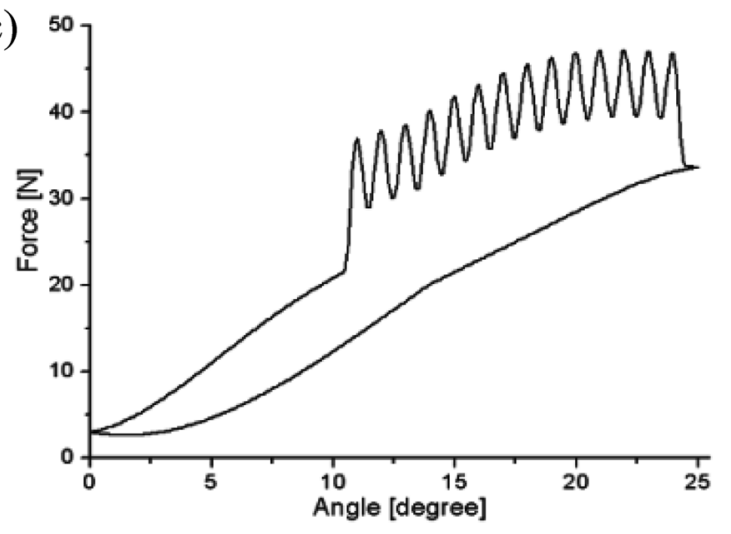

Fig. 13. Dynamic simulation reaction force according to pedal angle: (a) hysteresis curve in passive mode, (b) hysteresis curve upon active pedal force, (c) hysteresis curve upon active vibration force at the pedal rotating angle of $25^{\circ}$. force variation and average values of the cogging forces of the tubular actuator with and without a core actuator according to the movement of the shaft within the stroke length.

\subsection{Dynamic Simulation of AAP}

Fig. 12 shows the total schematic diagram and operation principle of the AAP. Dynamic analysis was performed with 3D dynamic analysis software RecurDyn with the AAP system counterforce curve proposed in Fig. 2. In Fig. 2, the counterforce is produced by the spring force in the passive condition, and the sum of the spring force and the TLA force is produced in the active condition. AL6061 is selected as the frame material. Oil-less busing is used between the stator and the mover so that the friction and moment between them can be ignored [7].

Fig. 13 shows the pedal counterforce curve as a function of the change of the pedal angle when the pedal is pressed or released. In Fig. 13(a), the maximum force is about $34 \mathrm{~N}$ and hysteresis is about $7 \sim 8 \mathrm{~N}$. These results satisfy the design conditions. Fig. 13(b) shows the result for the condition of $50 \mathrm{~N}$ thrust force production when the actuator works at $10^{\circ}$ in the active mode. Fig. 13(c) shows the result of the additional force and vibration force in the active mode. The additional force is steady-state at about $15 \mathrm{~N}$.

\section{Conclusions}

This research described an AAP system using a tubular linear actuator to reduce cogging force. Electromagnetic analysis was done to optimize the size of the actuator within the design conditions. Dynamic analysis was also performed to simulate the dynamic performance of the AAP.

A two- phase tubular linear actuator was suggested to satisfy required thrust force of $50 \mathrm{~N}$. Four design variables were selected and optimized (:) magnet length $22 \mathrm{~mm}$, magnet radius $9.7 \mathrm{~mm}$, airgap $1.1 \mathrm{~mm}$ and coil thickness $5.2 \mathrm{~mm}$. The suggested tubular linear actuator in AAP was simulated with RecurDyn software. The result of the two types of counterforce is satisfied.

The cogging force was also reduced to $0.01 \mathrm{~N}$ on average by the coreless actuator compared with a tubular core actuator. The reduced cogging force can be added to the thrust force to increase the efficiency of the actuator.

\section{Acknowledgement}

This research was supported by Yeungnam University research grants in 2009. 


\section{References}

[1] http://www.conti-online.com, Continental Co.

[2] http://www.rota.or.kr, Road Traffic Authority.

[3] J. Wang and D. Howe, IEEE Trans. Magn. 40, 3262 (2004).

[4] J. Y. Lee, J. H. Kim, S. M. Woo, and J. W. Lee, International Conference on Manufacturing, Machine Design and Tribology (2009).
[5] Laurentiu Encica, IEEE Trans. Ind. Appl. 44, 534 (2008).

[6] J. L. G. Janssen, J. J. H. Paulides, E. A. Lomonova, and A. J. A. Vandenput, IEEE Industry Applications Conference 502 (2007).

[7] N. Sclater, Nicholas P. Chironis, Mechanisms, and Mechanical Devices Sourcebook, McGraw-Hill, (2007) pp. 2145. 